\title{
EVALUASI KINERJA SISTEM INFORMASI CUTI ELEKTRONIK (SiCute) MENGGUNAKAN FRAMEWORK COBIT 5 PADA BADAN KEPEGAWAIAN, PENDIDIKAN DAN PELATIHAN DAERAH KOTA SALATIGA
}

\author{
Juen Ruth Djapandjatay ${ }^{1}$, Andeka Rocky Tanaamah ${ }^{2)}$, dan Penidas Fiodinggo Tanaem ${ }^{3)}$ \\ 1,2.3Sistem Informasi, Fakultas Teknologi Infomasi, Universitas Kristen Satya Wacana \\ ${ }_{1,2,3} \mathrm{Jl}$. DR. O. Notohamidjojo No.1, Salatiga, 50711 \\ E-mail : 682015029@student.uksw.edu ${ }^{1}$, atanaamah@uksw.edu ${ }^{2}$, penidas.fiodinggo@uksw.edu ${ }^{3}$
}

\begin{abstract}
ABSTRAK
Sistem Informasi Cuti Elektronik (SiCute) adalah sebuah aplikasi yang digunakan untuk mempermudah proses penyampaian semua informasi terkait pengajuan cuti yang dikelola oleh BKDIKLATDA Kota Salatiga.tujuan penelitian ini untuk mengevaluasi kinerja SiCute yang nantinya akan memberikan gambaran tentang capaian kinerja SiCute.penelitian ini menggunakan COBIT 5 sebagai alat ukur dalam melakukan evaluasi dan hanya berfokus pada satu domain yaitu MEA(Monitor,Evaluate and Assess). data yang diperoleh dari hasil kuisioner pada BKDIKLATDA Kota Salatiga yaitu tingkat kematangan domain MEA01 3,84, MEA02 3,82 dan MEA03 4, dengan nilai rata-rata akhir untuk keseluruhan domain MEA yaitu 3,88. Berdasarkan hasil penilaian tingkat kematangan dapat disimpulkan bahwa SiCute berada pada level 4(Predictable Process) yang berarti segala proses telah diljalankan dengan baik sesuai ketentuan yang ditetapkan untuk mencapai hasil yang diharapkan instansi.
\end{abstract}

Kata Kunci: SiCute, Evaluasi, COBIT 5, MEA, BKDIKLATDA Kota Salatiga

\section{PENDAHULUAN}

Perkembangan Teknologi Informasi memberikan banyak manfaat pada segala bidang. Penggunaan TI tidak terlepas dari adanya peran Sistem Informasi. Sistem Informasi merupakan sistem yang dipakai sebagai penyedia informasi untuk manajemen sebuah perusahaan atau instansi. PeranSI sangat dibutuhkan dalam menjalankan operasional sekaligus mempermudah kinerja perusahaan atau instansi.Pemanfaatan Sistem Informasi di berbagai bidang tentu banyak memiliki nilai lebih namun penggunaan SI yang kurang tepat dapat menimbulkan masalah. oleh sebab itu perlu dilakukannya evaluasi terhadap kinerja sistem informasi yang digunakan.

Sistem Informasi Cuti Elektronik(SiCute) adalah sebuah aplikasi yang digunakan untuk mempermudah proses penyampaian semua informasi terkait pengajuan cuti yang dikelola oleh BKDIKLATDA Kota Salatiga. dengan adanya aplikasi ini, diharapkan semua informasi terkait cuti dapat diakses secara terbuka oleh semua PNS Kota Salatiga, dan pegawai yang akan mengajukan permohonan cuti dapat langsung mendaftar pada website aplikasi SiCute ini. Aplikasi SiCute merupakan aplikasi berbasis website online yang dapat diakses kapan saja dan dimana saja oleh masing-masing PNS, pengelola kepegawaian SKPD, dan Admin Bkdiklatda menggunakan komputer/ laptop/ smartphone yang terhubung dengan internet. Aplikasi ini memiliki tujuan melakukan pelayanan dalam hal cuti kepada setiap Pegawai Negeri Sipil di Lingkungan Pemerintah Kota Salatiga di bidang kepegawaian secara transparan dan efisien (Manual Book SiCute 2018 - Google Docs.pdf, n.d.)
Penerapan Sistem Informasi Cuti Elektronik(SiCute) pada BKDIKLATDA Kota Salatiga,masih terdapat permasalahan yaitu belum pernah dilakukan evaluasi kinerja sistem secara menyeluruh untuk mengetahui seberapa optimal sistem bekerja sesuai tujuan karena proses evaluasi hanya dilakukan jika sistem mengalami masalah atau Trouble.

Dalam melakukan evaluasi kinerja sistem ini penulis menggunakan COBIT 5 sebagai alat ukur dalam melakukan evaluasi.COBIT 5 dapat membantu menciptakan nilai yang optimal dalam mengukur kinerja sebuah sistem informasi pada perusahaan atau intansi. penelitian ini berfokus pada satu domain yaitu MEA(Monitor,Evaluate and Assess). Dipilihnya domain MEA karena memiliki tujuan untuk melakukan pengawasan,evaluasi dan menilai segala proses yang berhubungan dengan manajemen TI. Tujuan penelitian ini untuk mengevaluasi kinerja SiCute yang nantinya akan memberikan gambaran tentang capaian kinerja SiCute.

Penelitian pertama yang terkait penelitian ini dilakukan oleh Stephanie Agathis Noya, Arya Dwika Cahyonodan Agustinus Fritz Wijaya, yang berjudul evaluasi kinerja tata kelola teknologi informasi pada dinas perindustrian dan tenaga kerja kota salatiga menggunakan COBIT 5.Tujuan dari penelitian ini untuk melakukan evaluasi terhadap kinerja tata kelola TI dan untuk memastikan efektivitas dan efisiensi TI dispernaker kota salatiga. Peneltian ini menggunakan COBIT 5 dengan domain proses diperoleh berdasarkan hasil pemetaan tujuan bisnis, tujuan TI, dan terkait proses TI.dalam menentukan responden menggunakan RACI Chart dan Process Capability Model(PCM) sebagai alat untuk 
mengukur hasil evaluasi.Hasil penelitian ini menunjukan bahwa Sistem Informasi Pasar Kerja(IPK) mencapai level 2 (Manage Process) dan level 3 (Established Process) (Noya, Cahyono, \& Wijaya, 2018.)

Penelitian selanjutnya dilakukan oleh Anneke Tri Andani dan Agustinus Fritz Wijaya, yang berjudul evaluasi kinerja sistem informasi e-filling menggunakan COBIT 5 pada kantor pelayanan pajak pratama kota salatiga.Tujuan dari penelitian ini untuk membantu KPP pratama salatiga mengetahui pencapaian dari tujuan bisnis dan memberikan rekomendasi untuk memenuhi kesenjangan antara tujuan dan pencapaian.Hasil penelitian ini menunjukan bahwa tiga proses dari COBIT 5 yang digunakan untuk menilai kinerja sistem informasi e-filling KPP pratama salatiga belum mencapai level 3 dengan nilai tingkat kematangan yaitu 1,22 berada pada level 1(Performed) yang berartisudah diimplementasi tetapi tidak dikontrol serta perencanaan yang terstruktur(Wijaya \& Andani, 2017)

Penelitian lainnya dilakukan oleh Niza Erika, Megawaty dan Siti Sauda, yang berjudul Implementasi framework COBIT 5 dalam evaluasi system informasi manajemen rumah sakit (SIMRS) di rumah sakit umum daerah kabupaten lahat. Tujuan dari penelitian ini untuk mengevaluasi system informasi manajemen rumah sakit(SIMRS) di rumah sakit umum daerah kabupaten lahat. Penelitian ini menggunakan model kapabilitas sebagai alat ukur terhadap jawaban responden pada kuisioner yang dibuat berdasarkan framework COBIT 5 dengan domain MEA sebagai acuan.Hasil penelitian ini menunjukan bahwa nilai tingkat kapabilitas SIMRS saat ini adalah 2,07 pada rentang 0-5(Erika, Megawaty, \& Sauda, 2017).

Berdasarkan ketiga penelitian terdahulu, ditemukan adanya persamaan dengan penelitian yang dilakukan penulis saat ini yaitu membahas tentang evaluasi kinerja menggunakan COBIT 5 dengan penentuan responden berdasarkan RACI Chart dan Process Capability Model(PCM) sebagai alat untuk mengukur hasil evaluasi sehingga dapat dijadikan acuan untuk penelitian ini. Namun terdapat perbedaan pada penelitian pertama dan kedua dengan peneletian ini yaitu penelitian ini hanya berfokus pada satu domain COBIT 5 yaitu MEA (Monitor,Evaluate and Assess).

\section{RUANG LINGKUP}

Dalam penelitian ini permasalahan mencakup :

1. Cakupan permasalahan dari penelitian ini adalah Pada Badan Kepegawaian,Pendidikan dan Pelatihan Daerah Kota Salatiga belum melakukan evaluasi kinerja sistem informasi secara menyeluruh untuk mengetahui seberapa optimal sistem bekerja sesuai tujuan karena evaluasi hanya dilakukan ketika sistem trouble.

2. Batasan penelitian ini mengacu pada hasil evaluasi kinerja sistem yang dilihat dari penilaian tingkat kematangan .
3. Rencana hasil yang didapat dari penelitian ini adalah memberikan gambaran tentang capaian kinerja SICUTE berdasarkan hasil perhitungan tingkat kematangan.

\section{BAHAN DAN METODE}

Berikut merupakan bahan penelitian, metode serta tahapan penelitian yang dilakukan

\subsection{Evaluasi Kinerja Sistem}

Evaluasi kinerja sistem adalah suatu penilaian sistematis terhadap suatu sistem untuk memberi gambaran apakah sistem yang sedang berjalan telah sesuai dengan yang dibutuhkan serta sesuai dengan tujuan suatu organisasi(Wijaya \& Andani, 2017)

\subsection{COBIT 5}

COBIT 5.0 adalah salah satu kerangka bisnis untuk tata kelola dan manajemen perusahaan IT. Versi evolusiner ini menggabungkan pemikiran terbaru dalam tata kelola perusahaan dan teknik manajemen, serta menyediakan prinsip-prinsip, praktek, alat-alat analisis dan model yang diterim secara global untuk membantu meningkatkan kepercayaan, dan nilai dari sistem informasi. COBIT 5 membangun dan memperluas COBIT 4.1 dengan mengintegrasikan kerangka besar lainnya, standar dan sumber daya,termasuk ISACA Val-IT dan Risiko TI, Technology Infrastructure Library (ITIL®) dan standar yang terkait dari International Organization for Standardization(ISO). 37 proses yang dimiliki COBIT 5 masing-masing domain memiliki beberapa proses. Dalam penelitian ini, penulis lebih fokus pada domain Monitor, Evaluate, and Assess (MEA). Domain MEA dapat melakukan pengontrolan atau pengawasan terhadap semua proses yang direncanakan. Semua proses yang berkaitan dengan TI perlu dinilai secara teratur untuk pengontrolan terhadap kualitas dari pengelolaan TI pada perusahaan (Belegur, Rudianto, \& Sitokdana, 2018).Berikut merupakan domain proses MEA :

1. MEA01 Monitor, Evaluate and Assess Performance and Conformance (Pengamatan, Evaluasi dan Menilai Kinerja dan Penyesuaian)

2. MEA02 Monitor, Evaluate and Assess The System of Internal Control (Pengamatan Evaluasi dan Menilai Sistem Pengendalian Internal)

3. MEA03 Monitor, Evaluate and Assess Compliance with External Requirements (Pengamatan, Evaluasi dan Menilai Kepatuhan dengan Persyaratan Eksternal.

\subsection{Process Capability Model(PCM)}

Proses kapabilitas model adalah kemampuan proses dalam meraih tingkat kapabilitas yang ditentukan oleh atribut proses. Model proses kapabilitas terbagi menjadi tingkatan-tingkatan yaitu (Kristanto dkk, 2016) :

1. Level 0 - Incomplete Process : Proses yang belum atau gagal diimplementasikan

2. Level 1 - Performed Process : Proses yang menentukan tercapainya tujuan.

3. Level 2-Managed Process : Proses yang mencakup perencanaan, monitor, dan penyesuaian 
4. Level 3 - Established Process : Proses yang sudah dibangun kemudian diimplementasikan untuk mencapai hasil dari proses.

5. Level 4 - Predictable Process : Proses yang sudahdibangun kemudian dioperasikan dengan batasan-batasan yang mampu meraih harapan dari proses

6. Level 5-Optimizing Process : Proses yang diprediksi secara terus-menerus ditingkatkan untuk memenuhi tujuan bisnis dan tujuan perusahaan.

\subsection{RACI Chart}

Penentuan responden dilakukan berdasarkan pemetaan Fungsi pada RACI Chart. RACI singkatan dari Responsible, Accountable, Consulted, Informed (Ambarwati \& Rusady, 2017).

1. Responsible berarti penanggung jawab atau orang yang bertanggung jawab.

2. Accountable merupakan pemilik kewenangan untuk menyetujui atau menerima pelaksanaan suatu kegiatan.

3. Consulted adalah pemberi konsultasi atau saran.

4. Informed yaitu penerima informasi atau yang harus diberi informasi atau yang harus mengetahui perkembangan dari suatu kegiatan yang dilakukan.

\subsection{Tahapan Penelitian}

Metode yang digunakan adalah mix method yang merupakan gabungan antara metode kualitatif dan kuantitatif dengan teknik pengambilan data berupa wawancara dan kuisioner. Adapun tahapan penelitian yang dilakukan penulis ditampilkan pada gambar 1 .

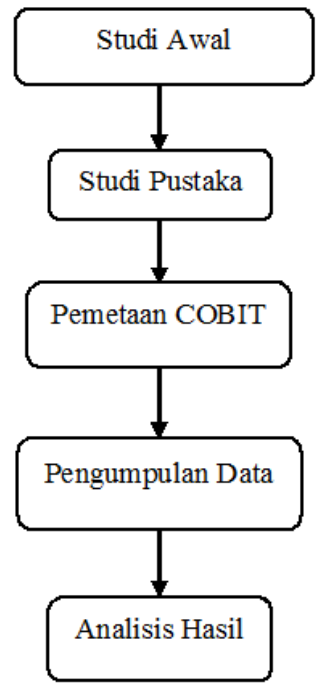

\section{Gambar 1. Tahapan Penelitian}

1. Studi Awal, pada tahap ini penulis menggali informasi untuk mendapatkan gambaran mengenai tujuan bisnis dan masalah dari Sistem Informasi Cuti Elektronik(SiCute) melalui wawancara dengan salah satu staf subbidang pembinaan dan kesejahtraan yang merupakan admin SiCute pada BKDIKLATDA SALATIGA.

2. Studi Pustaka, pada tahap ini penulis mencari pengetahuan tentang COBIT 5 yang nantinya akan menjadi dasar untuk melakukan penelitian ini.

3. Pemetaan COBIT. Pada tahap ini dilakukan lima proses yaitu identifikasi tujuan bisnis SiCute, identifikasi enterprise goals,identifikasi IT-related goals,pemetaan enterprise goals to IT-related goals dan identifikasi COBIT 5 proses.

4. Pengumpulan Data, pada tahap ini penulis menggunakan metode kuisioner yang dibuat berdasarkan domain MEA yang terpilih dari hasil pemetaan tujuan bisnis ke tujuan TI pada COBIT 5, kuisioner diberikan kepada staf yang memiliki keterkaitan dengan penggunaan SiCute.

5. Analisis Hasil, pada tahap ini dillakukan analisis terhadap data hasil perhitungan kuisioner menggunakan Process Capability Model(PCM) untuk mengetahui tingkat kematangan SICUTE dan nilai kesenjangan antara tingkat kematangan saat ini dan target yang diharapkan BKDIKLATDA Kota Salatiga. 


\section{PEMBAHASAN}

Berikut merupakan tahapan untuk menentukan COBIT 5 Proses :

\subsection{Proses COBIT 5}

1. Identifikasi Tujuan Sistem Informasi Cuti

Elektronik(SiCute)

Tahapan pertama,menetukan COBIT 5 Proses dengan mengidentifikasi tujuan bisnis dari Sistem Informasi Cuti Elektronik(SiCute) menggunakan empat perspektif Balance Scorecard yaitu Financial, Costumer, Internal, Learning and Growth. Hasil analisis ditampilkan pada tabel 1 :

Tabel.1 Identifikasi Tujuan Bisnis SiCute

\begin{tabular}{|l|l|}
\hline $\begin{array}{c}\text { Perspektif } \\
\text { Balance } \\
\text { Scorecard }\end{array}$ & \multicolumn{1}{c|}{ Tujuan SiCute } \\
\hline Financial & $\begin{array}{l}\text { Mengurangi penggunaan kertas } \\
\text { dalam proses pelaporan cuti }\end{array}$ \\
\hline Costumer & $\begin{array}{l}\text { Memberikan kemudahan dan } \\
\text { mempercepat pelayanan cuti } \\
\text { kepada PNS }\end{array}$ \\
\hline Internal & $\begin{array}{l}\text { Membantu mengoptimalkan } \\
\text { beberapa proses internal seperti } \\
\text { pengarsipan pengelola } \\
\text { kepegawaian untuk mengitung } \\
\text { TTP(Tunjangan Tambahan } \\
\text { Penghasilan) }\end{array}$ \\
\hline $\begin{array}{l}\text { Learning \& } \\
\text { Growth }\end{array}$ & $\begin{array}{l}\text { Meningkatkan kualitas SDM } \\
\text { melalui pembelajaran terkait } \\
\text { penggunaan SiCute }\end{array}$ \\
\hline
\end{tabular}

Tujuan SiCute berdasarkan perspektif financial yaitu penggunaan SiCute ini diharapkan dapat mengurangi penggunaan kertas dalam proses pelaporan cuti yang biasanya diperlukan minimal 3 kertas untuk setiap proses pengajuan cuti. berdasarkan perspektif costumer, SiCute diharapkandapat memberikan kemudahan dan mempercepat pelayanan cuti kepada PNS, hal ini tentu membuat setiap pelaporan cuti yang dilakukan menjadi lebih efisien dibandingkan sebelum menggunakan sistem. Berdasarkan perspektif internal, SiCute membantu mengoptimalkan beberapa proses internal seperti pengarsipan pengelola kepegawaian untuk menghitung TTP(Tunjangan Tambahan Penghasilan). Kemudian berdasarkan perspektifLearning \& Growth, tujuannya untuk meningkatkan Kualitas SDM melalui pembelajaran terkait SiCute.

2. Identifikasi Enterprise Goals

Tahapan Kedua, mengidentifikasi Enterprise Goals COBIT 5. Dalam menentukan Enterprise Goals, tujuan bisnis Sistem Informasi Cuti Elektronik(SiCute) selanjutnya disesuaikan dengan Enterprise Goals pada COBIT 5. Hasil ditampilkan pada tabel 2 :
Tabel 2.Analisis Keterhubungan Tujuan SICUTE dengan Enterprise Goals COBIT 5

\begin{tabular}{|c|c|c|}
\hline $\begin{array}{c}\text { Perspektif } \\
\text { Balance } \\
\text { Scorecard }\end{array}$ & $\begin{array}{c}\text { Enterprise } \\
\text { Goals Terpilih }\end{array}$ & Tujuan SiCute \\
\hline Financial & $\begin{array}{c}\text { EG 3 } \\
\text { Mengelola } \\
\text { resiko bisnis } \\
\text { (pengamanan } \\
\text { aset) }\end{array}$ & $\begin{array}{l}\text { Mengurangi } \\
\text { penggunaan } \\
\text { kertas dalam } \\
\text { proses pelaporan } \\
\text { cuti }\end{array}$ \\
\hline Costumer & $\begin{array}{c}\text { EG 7 } \\
\text { Kelangsungan } \\
\text { dan } \\
\text { ketersediaan } \\
\text { layanan bisnis }\end{array}$ & $\begin{array}{l}\text { Memberikan } \\
\text { Kemudahan dan } \\
\text { mempercepat } \\
\text { proses pelayanan } \\
\text { cuti kepada PNS }\end{array}$ \\
\hline Internal & $\begin{array}{c}\text { EG 14 } \\
\text { Produktifitas } \\
\text { operasional dan } \\
\text { staff }\end{array}$ & $\begin{array}{l}\text { Membantu } \\
\text { mengoptimalkan } \\
\text { beberapa proses } \\
\text { internal seperti } \\
\text { pengarsipan } \\
\text { pengelola } \\
\text { kepegawaian } \\
\text { untuk mengitung } \\
\text { TTP(Tunjangan } \\
\text { Tambahan } \\
\text { Penghasilan) }\end{array}$ \\
\hline $\begin{array}{l}\text { Learning } \\
\text { \& Growth }\end{array}$ & $\begin{array}{c}\text { EG } 16 \\
\text { Orang yang } \\
\text { terampil dan } \\
\text { termotivasi }\end{array}$ & $\begin{array}{l}\text { Meningkatkan } \\
\text { Kualitas SDM } \\
\text { melalui } \\
\text { pembelajaran } \\
\text { terkait } \\
\text { penggunaan } \\
\text { SiCute }\end{array}$ \\
\hline
\end{tabular}

Hasil analisis keterhubungan antara tujuan SiCute dengan Enterprise Goals COBIT 5 yaitu Enterprise Goals(EG) 3mengelola resiko bisnis (pengamanan asset),EG 7 kelangsungan dan ketersediaan layanan bisnis,EG 14 produktifitas operasional dan staf, EG 16 orang yang terampil dan termotivasi.

\section{Identifikasi IT-Related Goals}

Tahapan ketiga, berdasarkan hasil analisis keterhubungan pada tabel 2 , kemudian akan ditentukan IT-Related Goals berdasarkan EG(Enterprise Goals) terpilih. Hasil identifikasi ditampilkan pada tabel 3.

Tabel 3.IT-Related Goals Terpilih

\begin{tabular}{|c|c|c|}
\hline No & Kode EG Terpilih & IT Related Goals \\
\hline 1 & EG 3 & $4,10,16$ \\
\hline 2 & EG 7 & $4,10,14$ \\
\hline 3 & EG 14 & 8,16 \\
\hline 4 & EG 16 & 16 \\
\hline
\end{tabular}

Hasil identifikasi IT-Related Goals adalah IT-G 4 Mengelola resiko bisnis terkait TI, IT-G 8 Penggunaan aplikasi, informasi \& solusi teknologi yang memadai,ITG 10 Keamanan informasi, pengolahan infrastruktur \& aplikasi,IT-G 14 Ketersediaan informasi yang handal \& berguna untuk pengambilan keputusan dan nomor 16 Kompeten dan termotivasi bisnis. 
4. Pemetaan Enterprise Goals to IT-Related Goals

Tahapan keempat, dilakukan pemetaan antara Enterprise Goals to IT-Related Goals. Hasil Pemetaan ditampilkan pada tabel 4 :

Tabel 4. Pemetaan Enterprise Goals to ITRelated Goals

\begin{tabular}{|l|c|c|c|c|}
\hline & EG & EG & EG & EG16 \\
& 3 & 7 & 14 & \\
\hline IT-G1 & S & S & & S \\
\hline IT-G2 & S & & & \\
\hline IT-G3 & S & & & S \\
\hline IT-G4 & P & P & & S \\
\hline IT-G5 & & & S & \\
\hline IT-G6 & S & & & \\
\hline IT-G7 & S & S & & S \\
\hline IT-G8 & S & S & P & S \\
\hline IT-G9 & S & & S & S \\
\hline IT-G10 & P & P & & \\
\hline IT-G11 & & & S & \\
\hline IT-G12 & S & & S & \\
\hline IT-G13 & S & & & \\
\hline IT-G14 & S & P & & \\
\hline IT-G15 & S & & & \\
\hline IT-G16 & P & & P & P \\
\hline IT-G17 & & & & S \\
\hline
\end{tabular}

Berdasarkan hasil pemetaan, terdapat lima tujuan IT yang memiliki keterhubungan yang kuat dengan Enterprise Goals ditandai dengan huruf P (Primary) artinya memiliki hubungan yang kuat sedangkan $\mathrm{S}$ (Secondary) artinya memiliki hubungan yang tidak kuat. .Karena fokus penelitian ini hanya menggunakan domain MEA maka dari lima tujuan IT yang terpilih hanya diambil satu tujuan IT yang memiliki keterhubungan yang kuat dengan domain MEA yaitu IT-G4

5. Identifikasi COBIT 5 Proses

tahapan kelima, menentukan COBIT 5 proses. Hasil identifikasi ditampilkan pada tabel 5 :

Tabel 5. COBIT 5 Proses Terpilih

\begin{tabular}{|c|c|l|}
\hline No & $\begin{array}{c}\text { Kode } \text { IT- } \\
\text { Related } \\
\text { Goals }\end{array}$ & \multicolumn{1}{c|}{ COBIT 5 Proses } \\
\hline 1 & 4 & $\begin{array}{l}\text { MEA01, } \\
\text { MEA02,MEA03 }\end{array}$ \\
\hline
\end{tabular}

Berdasarkan hasil identifikasi pada tabel 5, COBIT 5 Proses yang terpilih yaitu MEA01,MEA02 dan MEA03.

6. Identifikasi Responden Berdasarkan RACI Chart

Pada tahap ini dilakukan identifikasi terhadap responden berdasarakan RACI Chart. Hasil ditampilkan pada tabel 6 :
Tabel 6.Identifikasi Responden berdasarkan RACI Chart

\begin{tabular}{|l|l|}
\hline \multicolumn{1}{|c|}{ Peran RACI } & \multicolumn{1}{c|}{ Responden } \\
\hline Reponsible & $\begin{array}{l}\text { Staf subbidang pembinaan dan } \\
\text { kesejahteraan }\end{array}$ \\
\hline Accountable & $\begin{array}{l}\text { Kepala bidang pembinaan dan } \\
\text { Mutasi }\end{array}$ \\
\hline Consulted & $\begin{array}{l}\text { Staf subbidang pengelolaan } \\
\text { data dan formasi }\end{array}$ \\
\hline Informed & $\begin{array}{l}\text { Kepala bidang } \\
\text { pembinaan dan Mutasi }\end{array}$ \\
\hline
\end{tabular}

Hasil identifikasi responden menunjukan bahwa terdapat lima staf yang memiliki keterhubungan dengan penggunaan SiCute sehingga dapat menjadi responden dalam penelitian ini.Staf subbidang pembinaan dan dan kesejahteraan, Kepala bidang pembinaan dan Mutasi, Staf subbidang pengelolaan data dan formasi.

\subsection{Hasil Kematangan dan evaluasi}

Berikut merupakan hasil dari penelitian :

1. Tingkat Kematangan Domain MEA

Berdasarkan hasil kuisioner evaluasi kinerja Sistem Informasi Cuti Elektronik (SiCute) pada BKDIKLATA Kota Salatiga,maka hasil penilaian tingkat kematangan setiap domain MEA sebagai berikut :

1) Domain proses MEA01 (Memantau, Mengevaluasi \& Menilai kinerja serta kesesuaian).Hasil penilaian ditampilkan pada tabel 7 :

Tabel 7.Tingkat kematangan domain MEA01

\begin{tabular}{|c|c|}
\hline Domain Proses & Tingkat Kematangan \\
\hline MEA01.01 & 3,60 \\
\hline MEA02.02 & 3,20 \\
\hline MEA03.03 & 4,20 \\
\hline MEA04.04 & 4,20 \\
\hline MEA.05.05 & 4,00 \\
\hline $\begin{array}{c}\text { Rata-rata } \\
\text { kematangan }\end{array}$ & 3,84 \\
\hline
\end{tabular}

Tingkat Kematangan dari penilaian domain MEA01 yaitu 3,84 . Hal tersebutmenunjukan bahwa proses ini berada pada pada level 4(Predictable Process), artinya BKDIKLATDA Kota Salatiga sudah melakukan kegiatan memantau, mengevaluasi dan menilai kesesuaian proses kinerja Sistem Informasi Cuti Elektronik(SiCute) dengan baik dan telah diprediksi untuk mencapai hasil yang diinginkan. 
2) Domain proses MEA02 (Memantau, Mengevaluasi \& Menilai sistem pengendalianinternal)

Hasil penilaian ditampilkan pada tabel 8 :

Tabel 8.Tingkat kematangan domain MEA02

\begin{tabular}{|c|c|}
\hline $\begin{array}{c}\text { Domain } \\
\text { Proses }\end{array}$ & Tingkat Kematangan \\
\hline MEA02.01 & 3,80 \\
\hline MEA02.02 & 3,60 \\
\hline MEA02.03 & 3,40 \\
\hline MEA02.04 & 3,80 \\
\hline MEA02.05 & 4,00 \\
\hline MEA02.06 & 4,20 \\
\hline MEA02.07 & 4,00 \\
\hline MEA02.08 & 3,80 \\
\hline $\begin{array}{c}\text { Rata-rata } \\
\text { kematangan }\end{array}$ & 3,82 \\
\hline
\end{tabular}

Tingkat Kematangan dari penilaian domain MEA02 yaitu 3,82 . Hal tersebut menunjukan bahwa proses ini berada pada level 4 (Predictable process), artinya BKDIKLATDA Kota Salatiga sudah melakukan kegiatan memantau, mengevaluasi dan menilai lingkungn pengendalian internal untuk mengidentifikasi adanya kekurangan kontrol pada Sistem Informasi Cuti Elektronik (SiCute) dengan baik dan telah diprediksi untuk mencapai hasil yang diinginkan.

3) Domain proses MEA03(Memantau, mengevaluasi \& menilai kepatuhan terhadap kebutuhan eksternal). Hasil penilaian ditampilkan pada tabel 9 :

\section{Tabel 9.Tingkat kematangan domain MEA03}

\begin{tabular}{|c|c|}
\hline Domain Proses & $\begin{array}{c}\text { Tingkat } \\
\text { Kematangan }\end{array}$ \\
\hline MEA03.01 & 4,00 \\
\hline MEA03.02 & 4,20 \\
\hline MEA03.03 & 4,00 \\
\hline MEA03.04 & 3,80 \\
\hline $\begin{array}{c}\text { Rata-rata } \\
\text { kematangan }\end{array}$ \\
\hline
\end{tabular}

Tingkat Kematangan dari penilaian domain MEA03 yaitu 4. Hal tersebut menunjukan bahwa proses ini berada pada level 4 (Predictable Process), artinya BKDIKLATDA Kota Salatiga sudah melakukan kegiatan memantau, mengevaluasi dan menilai kepatuhan terhadap kebutuhan ekternalsesuai dengan undang-undang dan peraturan-peraturan dengan baik dan telah diprediksi untuk mencapai hasil yang diinginkan.
2. Tingkat kematangan seluruh domain MEA

Berikut merupakan tingkat kematangan dari seluruh domain MEA pada tabel 10 :

Tabel 10.Tingkat kematangan seluruh domain

\begin{tabular}{|c|c|c|c|}
\hline \multirow{2}{*}{$\begin{array}{c}\text { Domain } \\
\text { Proses }\end{array}$} & \multicolumn{3}{|c|}{ Tingkat Kematangan } \\
\cline { 2 - 4 } & $\begin{array}{c}\text { Kondis } \\
\text { i saat } \\
\text { ini }\end{array}$ & $\begin{array}{c}\text { Target } \\
\text { Harapan }\end{array}$ & $\begin{array}{c}\text { Kesenj } \\
\text { angan/ } \\
\text { GAP }\end{array}$ \\
\hline MEA01 & 3,84 & 5 & 1,16 \\
\hline MEA02 & 3,82 & 4 & 0,18 \\
\hline MEA03 & 4 & 4 & 0 \\
\hline $\begin{array}{c}\text { Rata-rata } \\
\text { kematangan }\end{array}$ & 3,88 & & \\
\hline
\end{tabular}

Dari hasil penilaian tingkat kematangan seluruh domain MEA, menunjukan bahwa Sistem Informasi Cuti Elektronik(SiCute) memiliki rata-rata tingkat kematangan yaitu 3,88 berada pada level 4 (Predictable Process).diartikan bahwa, dalam penerapan SiCute pada BKDIKLATDA Kota Salatiga telah dijalankan dengan baik sesuai dengan ketentuan yang ditetapkan untuk mencapai hasil yang diharapkan instansi.

\section{Analisis Kesenjangan}

Analisis kesenjangan bertujuan untuk mengetahui kesenjangan antara tingkat kematangan Sistem Informasi Cuti Elektronik(SiCute) saat ini dan target yang diharapakan oleh BKDIKLTADA Kota Salatiga.tingkat keenjangan ditampilkan pada gambar 2 :

$$
\begin{aligned}
& \cdots \cdot . \cdot \text { KENYATAAN } \cdots \bullet \cdot . \cdot \text { HARAPAN } \\
& \cdots \cdots \text { GAP }
\end{aligned}
$$

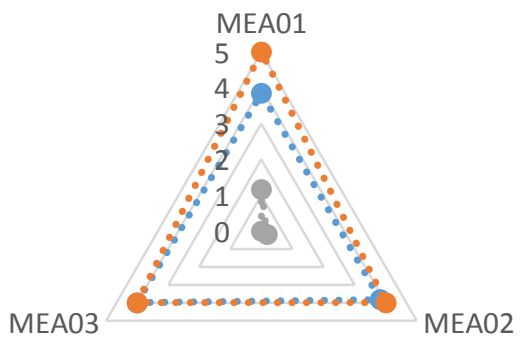

\section{Gambar 2.Radar Chart kesenjangan tingkat kematangan}

Pada setiap domain MEA memilikitarget pencapaian masing-masing. target yang ingin dicapai pada domain MEA 01 berada pada level 5 (Optimizing Process) sedangkan MEA 02 dan MEA03 berada pada level 4 (Predictable Process). 
Berdasarkan hasil penilaian tingkat kematangan dapat disimpulkan bahwa masih terdapat kesenjangan antara tingkat kematangan SiCute saat ini dengan target yang diharapkan BKDIKLATDA Kota Salatiga. tingkat kematangan pada domain MEA01 yaitu 3,84 yang berada pada level 4 sedangkan target yang diharapkan adalah level 5 sehingga ditemukan nilai kesenjangansebesar 1,16. Olehsebab itu, pihak BKDIKLATDA Kota Salatiga perlu meningkatkan kinerjanya dalam melakukan kegiatan memantau,mengevaluasi dan menilai kesesuaian proses kinerja SiCute agar operasional dapat berjalan dengan lancar.

\section{KESIMPULAN}

COBIT 5 membantu menyediakan kerangka kerja untuk mengevaluasi dan mengukur kinerja sistem informasi. Penerapan Sistem Informasi Cuti Elektronik (SiCute) pada BKDIKLATDA Kota Salatiga sudah dijalankan dengan baik oleh instansi sesuai dengan ketentuan yang telah ditetapkan untuk mencapai hasil yang diharapkan instansi, dapat dilihat berdasarkan hasil perhitungan tingkat kematangan domain MEA01,MEA02 dan MEA03 diperoleh nilai rata-rata yaitu 3,88 yang artinya SiCute telah berada pada level 4(Predictable Process). Akan tetapi masih terdapat sedikit kesenjangan pada tingkat kematangan SiCuteyang dilihat dari tingkat kematangandomain MEA01 yang berada pada level 4 sedangkan target yang diharapkan oleh BKDIKLATDA Kota Salatiga berada pada level 5. Berdasarkan temuan yang diperoleh, maka diharapkan BKDIKLATDA Kota Salatiga perlu meningkatkan pemantauan dan melakukan evaluasi secara berkala terhadap kesesuaian kinerja SiCute agar operasional dapat berjalan sesuai dengan target yang telah diharapakan

\section{SARAN}

Bagi peneliti selanjutnya yang akan melakukan penelitian tentang kinerja SiCute pada BKDIKLATDA Kota Salatiga dapat menggunakan domain COBIT 5 yang berbeda agar memperoleh hasil yang lebih lengkap.

\section{DAFTAR PUSTAKA}

Ambarwati, A., \& Rusady, R.2017. Analisis Implementasi Teknologi Informasi pada Domain Deliver and Support di PT. RDPI. Jurnal INFORM, 2(2). https://doi.org/10.25139/ojsinf.v2i2.315

Belegur, J. A. I., Rudianto, C., \& Sitokdana, M. 2018. Evaluasi Tata Kelola Teknologi Informasi Dinas Pariwisata dan Kebudayaan Kota Ambon Menggunakan Framework Cobit 5.0 pada Domain Monitor, Evaluate And Asses (MEA). Aiti, 15(2), 107-114. https://doi.org/10.24246/aiti.v15i2.107114

Erika, N., Megawaty, \& Sauda, S.2017. Implementasi Framework Cobit 5 Dalam Evaluasi Sisstem Informasi Manajemen Rumah Sakit ( Simrs ). Jurnal Teknik Informatika, 1-8. http://if.binadarma.ac.id/sipi/jurnal/Jurnaljurnal\%20niza\%20erika.pdf

Kristanto, T., Lestari, L A., \& Sulistyowati.2016. Analisis Tingkat Kematangan E-govermment Menggunakan Framework COBIT 5(Studi Kasus : Dinas Perdagangan dan Perindustrian Kota Surabaya) .Seminar Nasional Sistem Informasi Indonesia. $1 \quad$ november 2016. http://is.its.ac.id/pubs/oajis/index.php/file/downloa d_file/1664

Manual Book SiCute 2018 - Google Docs.pdf. (n.d.).

Noya, S. A., Cahyono, A. D., \& Wijaya, A. F. (n.d.). Dinas Perindustrian Dan Tenaga Kerja Kota Salatiga Menggunakan Cobit 5. 3(2018), 1-14.

Wijaya, A. F., \& Andani, A. T. 2017. Evaluasi Kinerja Sistem informasi E-Filing Menggunakan COBIT 5 Pada Kantor Pelayanan Pajak Pratama Kota Salatiga.Jurnal Terapan Teknologi Informasi, 1(1), 61-70. https://doi.org/10.1186/s13104-017-3108-5 